\title{
Article
}

\section{Glutamine for induction of remission in Crohn's disease.}

\author{
Akobeng, Anthony, Elawad, M and Gordon, Morris \\ Available at http://clok.uclan.ac.uk/13855/ \\ Akobeng, Anthony, Elawad, M and Gordon, Morris ORCID: 0000-0002-1216- \\ 5158 (2016) Glutamine for induction of remission in Crohn's disease. \\ Cochrane Library .
}

It is advisable to refer to the publisher's version if you intend to cite from the work. http://dx.doi.org/10.1002/14651858.CD007348.pub2

For more information about UCLan's research in this area go to

http://www.uclan.ac.uk/researchgroups/ and search for < name of research Group>.

For information about Research generally at UCLan please go to http://www.uclan.ac.uk/research/

All outputs in CLoK are protected by Intellectual Property Rights law, including Copyright law. Copyright, IPR and Moral Rights for the works on this site are retained by the individual authors and/or other copyright owners. Terms and conditions for use of this material are defined in the policies page.

\section{CLoK}

Central Lancashire online Knowledge www.clok.uclan.ac.uk

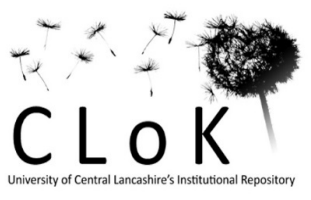




\title{
Glutamine for induction of remission in Crohn's disease (Review)
}

\author{
Akobeng AK, Elawad M, Gordon M
}

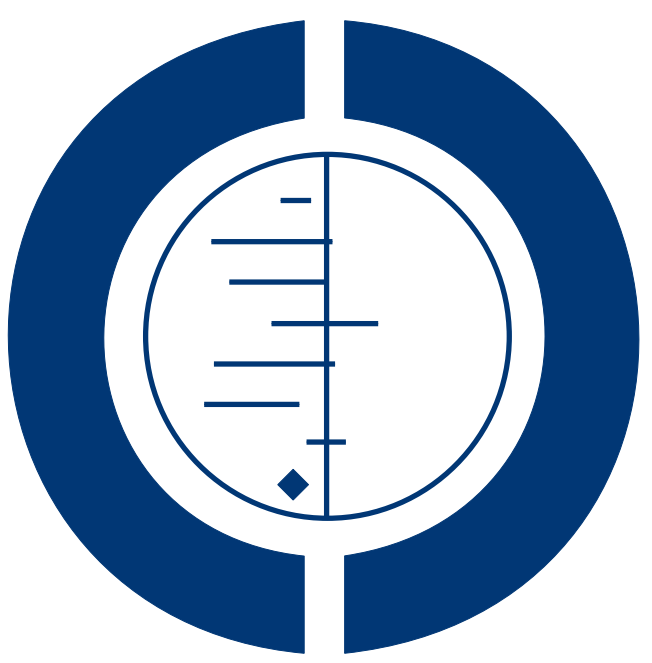

THE COCHRANE
COLLABORATION $^{\circledR}$

This is a reprint of a Cochrane review, prepared and maintained by The Cochrane Collaboration and published in The Cochrane Library 2016, Issue 2

http://www.thecochranelibrary.com

\section{WILEY}


TABLE OF CONTENTS

HEADER . . . . . . . . . . . . . . . . . . . . . . . . . . . . . . . . . . . . 1

ABSTRACT . . . . . . . . . . . . . . . . . . . . . . . . . . . . . . . . . . . . . . . . 1

PLAIN LANGUAGE SUMMARY . . . . . . . . . . . . . . . . . . . . . . . . . . . . . . . . . . .

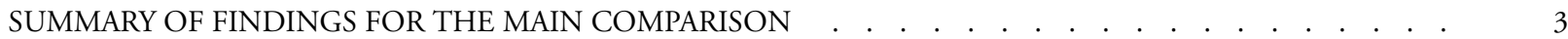

BACKGROUND . . . . . . . . . . . . . . . . . . . . . . . . . . . . . . . . . . . . . . . 4

OBJECTIVES . . . . . . . . . . . . . . . . . . . . . . . . . . . . . . . . . . . . . . . . . . . . . . . . . .

METHODS . . . . . . . . . . . . . . . . . . . . . . . . . . . . . . . . . . . . . . 4

RESUlTS . . . . . . . . . . . . . . . . . . . . . . . . . . . . . . . . . . . . 6

Figure 1. . . . . . . . . . . . . . . . . . . . . . . . . . . . . . . . . . . . 7

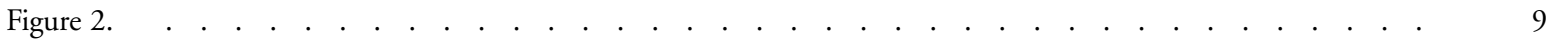

Figure 3. . . . . . . . . . . . . . . . . . . . . . . . . . . . . . . . . . . . 10

Figure $4 . \quad$. . . . . . . . . . . . . . . . . . . . . . . . . . . . . . . . . . . . . 10

Figure 5. . . . . . . . . . . . . . . . . . . . . . . . . . . . . . . . . . . . . . 411

DISCUSSION . . . . . . . . . . . . . . . . . . . . . . . . . . . . . . . . . . . . . . . . .

AUTHORS' CONCLUSIONS . . . . . . . . . . . . . . . . . . . . . . . . . . . . . . . . 12

ACKNOWLEDGEMENTS . . . . . . . . . . . . . . . . . . . . . . . . . . . . . . . . . 12

REFERENCES . . . . . . . . . . . . . . . . . . . . . . . . . . . . . . . . . . . . . . 12

CHARACTERISTICS OF STUDIES . . . . . . . . . . . . . . . . . . . . . . . . . . . . . . . . 14

DATA AND ANALYSES . . . . . . . . . . . . . . . . . . . . . . . . . . . . . . . . . . . . . . . . . . . . . . . 18

Analysis 1.1. Comparison 1 Glutamine-enriched diet versus standard diet, Outcome 1 Clinical remission. . . . . . 18

Analysis 1.2. Comparison 1 Glutamine-enriched diet versus standard diet, Outcome 2 Intestinal permeability. . . . 19

Analysis 1.3. Comparison 1 Glutamine-enriched diet versus standard diet, Outcome 3 Central catheter infections. . 19

APPENDICES . . . . . . . . . . . . . . . . . . . . . . . . . . . . . . . . . . . . 19

CONTRIBUTIONS OF AUTHORS . . . . . . . . . . . . . . . . . . . . . . . . . . . . . . . . . 20

DECLARATIONS OF INTEREST . . . . . . . . . . . . . . . . . . . . . . . . . . . . . . . . . . 20

DIFFERENCES BETWEEN PROTOCOL AND REVIEW . . . . . . . . . . . . . . . . . . . . . . . . . . . . . . .

Glutamine for induction of remission in Crohn's disease (Review)

Copyright $\odot 2016$ The Cochrane Collaboration. Published by John Wiley \& Sons, Ltd. 


\title{
[Intervention Review]
}

\section{Glutamine for induction of remission in Crohn's disease}

\author{
Anthony K Akobeng ${ }^{1,2}$, Mamoun Elawad ${ }^{1}$, Morris Gordon ${ }^{3}$ \\ ${ }^{1}$ Sidra Medical \& Research Center, Doha, Qatar. ${ }^{2}$ University of Manchester, Manchester, UK. ${ }^{3}$ School of Medicine and Dentistry, \\ University of Central Lancashire, Preston, UK \\ Contact address: Anthony K Akobeng, Sidra Medical \& Research Center, PO Box 26999, Doha, Qatar. aakobeng@sidra.org. \\ akobeng@aol.com.
}

Editorial group: Cochrane IBD Group.

Publication status and date: New, published in Issue 2, 2016.

Review content assessed as up-to-date: 15 November 2015.

Citation: Akobeng AK, Elawad M, Gordon M. Glutamine for induction of remission in Crohn's disease. Cochrane Database of Systematic Reviews 2016, Issue 2. Art. No.: CD007348. DOI: 10.1002/14651858.CD007348.pub2.

Copyright @ 2016 The Cochrane Collaboration. Published by John Wiley \& Sons, Ltd.

\begin{abstract}
A B S T R A C T
Background

Crohn's disease is a chronic relapsing condition of the alimentary tract with a high morbidity secondary to bowel inflammation. Glutamine plays a key role in maintaining the integrity of the intestinal mucosa and has been shown to reduce inflammation and disease activity in experimental models of Crohn's disease.
\end{abstract}

\section{Objectives}

To evaluate the efficacy and safety of glutamine supplementation for induction of remission in Crohn's disease.

\section{Search methods}

We searched the following databases from inception to November 15, 2015: MEDLINE, EMBASE, the Cochrane Central Register of Controlled Trials, and the Cochrane IBD Group Specialised Register. Study references were also searched for additional trials. There were no language restrictions.

\section{Selection criteria}

Randomised controlled trials (RCTs) that compared glutamine supplementation administered by any route to a placebo, active comparator or no intervention in people with active Crohn's disease were considered for inclusion.

\section{Data collection and analysis}

Two authors independently extracted data and assessed the methodological quality of the included studies. The Cochrane risk of bias tool was used to assess methodological quality. The primary outcome measure was clinical or endoscopic remission. Secondary outcomes included intestinal permeability, clinical response, quality of life, growth in children and adverse events. Risk ratios and $95 \%$ confidence intervals were calculated for dichotomous outcomes. The overall quality of the evidence supporting the primary outcome was evaluated using the GRADE criteria.

\section{Main results}

Two small RCTs (total 42 patients) met the inclusion criteria and were included in the review. One study (18 patients) compared four weeks of treatment with a glutamine-enriched polymeric diet ( $42 \%$ amino acid composition) to a standard polymeric diet ( $4 \%$ amino acid composition) with low glutamine content in paediatric patients $(<18$ years of age) with active Crohn's disease. The other study (24 patients) compared glutamine-supplemented total parenteral nutrition to non-supplemented total parenteral nutrition in adult 
patients (> 18 years of age) with acute exacerbation of inflammatory bowel disease. The paediatric study was rated as low risk of bias. The study in adult patients was rated as unclear risk of bias for blinding and low risk of bias for all other items. It was not possible to pool data for meta-analysis because of significant differences in study populations, nature of interventions, and the way outcomes were assessed. Data from one study showed no statistically significant difference in clinical remission rates at four weeks. Forty-four per cent (4/9) of patients who received a glutamine-enriched polymeric diet achieved remission compared to 56\% (5/9) of patients who received a standard low-glutamine polymeric diet (RR $0.80,95 \%$ CI 0.31 to 2.04 ). A GRADE analysis indicated that the overall quality of evidence for this outcome was low due to serious imprecision ( 9 events). In both included studies, no statistically significant changes in intestinal permeability were found between patients who received glutamine supplementation and those who did not. Neither study reported on clinical response, quality of life or growth in children. Adverse event data were not well documented. There were no serious adverse events in the paediatric study. The study in adult patients reported three central catheter infections with positive blood cultures in the glutamine group compared to none in the control group (RR 7.00, 95\% CI 0.40 to 122.44).

\section{Authors' conclusions}

Currently there is insufficient evidence to allow firm conclusions regarding the efficacy and safety of glutamine for induction of remission in Crohn's disease. Data from two small studies suggest that glutamine supplementation may not be beneficial in active Crohn's disease but these results need to be interpreted with caution as they are based on small numbers of patients. This review highlights the need for adequately powered randomised controlled trials to investigate the efficacy and safety of glutamine for induction of remission in Crohn's disease.

\section{PLAIN LANGUAGE SUMMARY}

\section{Glutamine for treatment of active Crohn's disease}

What is Crohn's disease?

Crohn's disease is a chronic inflammatory disorder of the intestines which has periods of inactivity and periods when it flares up. Crohn's disease can affect any part of the digestive tract, from the mouth to the anus. The most common symptoms of the disease include abdominal pain, non-bloody diarrhoea and weight loss. When people with Crohn's disease are experiencing symptoms of the disease it is said to be 'active'; periods when the symptoms stop are called 'remission'.

What is glutamine?

Glutamine is an amino acid that plays a key role in maintaining the integrity of the intestinal mucosa (lining of the intestines) and has been shown to reduce inflammation and disease activity in animal models of Crohn's disease. It has therefore been suggested that glutamine may reduce intestinal inflammation in people with Crohn's disease.

What did the researchers investigate?

The researchers investigated whether glutamine is effective for inducing remission in people with active Crohn's disease and whether this treatment causes any harms (side effects). The researchers searched the medical literature up to November 15, 2015.

What did the researchers find?

The researchers identified two randomised controlled trials (total 42 participants) that investigated the role of glutamine for the treatment of active Crohn's disease. One study (18 patients) compared four weeks of treatment with a glutamine-enriched polymeric $\operatorname{diet}(42 \%$ amino acid composition) to a standard polymeric diet ( $4 \%$ amino acid composition) with low glutamine content in paediatric patients ( $<18$ years of age) with active Crohn's disease. Participants were encouraged to consume the diet orally. If this was not possible the diet was administered via a fine-bore nasogastric tube. The other study (24 participants) compared glutamine-supplemented total parenteral nutrition (TPN) to non-supplemented TPN in adult patients (> 18 years of age) with sudden worsening of inflammatory bowel disease. The TPN diet was administered intravenously via a central catheter (a thin tube) for at least one week. Both studies were generally high quality. Neither study demonstrated any beneficial effects for glutamine. Side effects were not well documented in the two studies. There were no serious side effects noted in the paediatric study. The study in adult patients reported three central catheterrelated blood infections in the glutamine group compared to none in the non-glutamine control group. Currently, there is insufficient evidence to allow any firm conclusions regarding the effectiveness and harms of glutamine for the treatment of active Crohn's disease.

Glutamine for induction of remission in Crohn's disease (Review) 


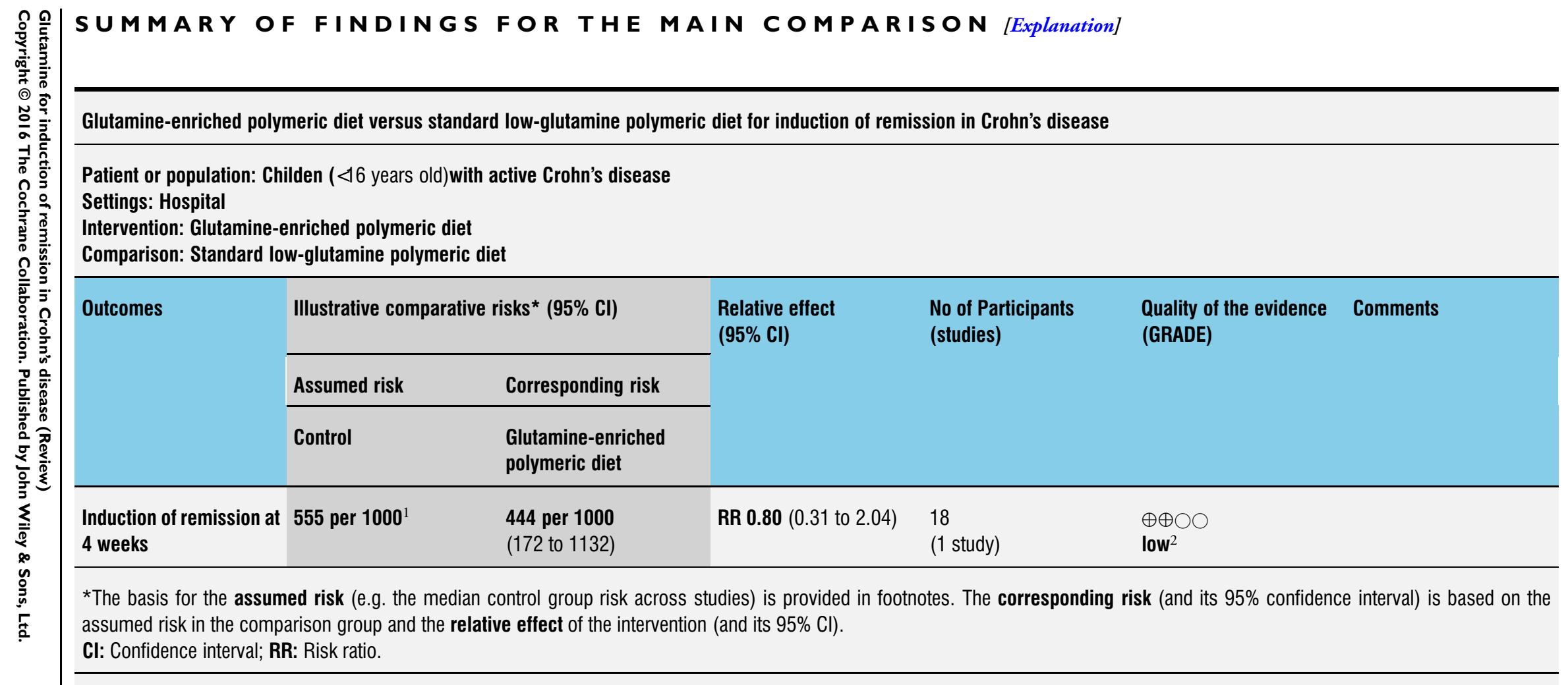

GRADE Working Group grades of evidence

High quality: Further research is very unlikely to change our confidence in the estimate of effect.

Moderate quality: Further research is likely to have an important impact on our confidence in the estimate of effect and may change the estimate.

Low quality: Further research is very likely to have an important impact on our confidence in the estimate of effect and is likely to change the estimate.

Very low quality: We are very uncertain about the estimate.

${ }^{1}$ The control group estimate comes from the control arm of the included study on children with active Crohn's disease.

${ }^{2}$ Downgraded two levels due to small sample size and low event rates resulting in serious imprecision (9 events). 


\section{B A C K G R O U N D}

Crohn's disease is a chronic relapsing inflammatory condition of the alimentary tract characterised by gut mucosal inflammation, enhanced pro-inflammatory cytokine activity, increased gut permeability and poor nutrition secondary to decreased intake and to increased catabolic losses (Katz 1989). Glutamine, a conditionally essential amino acid in catabolic states, is the principal respiratory substrate for enterocytes (Windmueller 1978). It is known to play a key role in maintaining the integrity of the intestinal mucosa. Glutamine supplementation has been shown to reduce intestinal permeability (Hond 1999), prevent mucosal atrophy and maintain gut integrity (Van der Hurst 1993). It spares mobilisation of glutamine from skeletal muscle and thereby improves nitrogen balance (Stehle 1989).

Protein turnover is increased in active Crohn's disease (Thomas 1992), and subjects are in a state of catabolism (Kangas 1986). Low plasma glutamine levels have been described in patients with Crohn's disease (Thomas 1991). This may be due to enhanced utilisation of glutamine by the diseased intestinal mucosa (Lacey 1990). The body's requirement for glutamine may exceed the supply causing a state of glutamine deficiency. This nature of conditional essentialness has been demonstrated in other catabolic states such as burns, trauma and sepsis (Hall 1996).

In experimental animal models of Crohn's disease, glutamine supplementation prevented macroscopic ileitis and increased intestinal glutathione status (Sido 2006), reduced inflammation, prevented weight loss, improved nitrogen balance and reduced disease activity (Fox 1988). Glutamine has been shown to reduce bacterial translocation in an animal model (Fujita 2005), which may have important implications in the setting of gut mucosal inflammation as seen in Crohn's disease. In vitro, glutamine reduces the production of the pro-inflammatory cytokines interleukin- 6 and interleukin-8, and enhances the production of the anti-inflammatory cytokine, interleukin-10 in human intestinal mucosa (Coeffier 2003). Down-regulation of chemokines by glutamine could also contribute to its therapeutic potential by reducing intestinal inflammation during critical illnesses (Marion 2004).

Considering that glutamine may have positive nutritional, metabolic and immunologic benefits with respect to Crohn's disease, it has been trialled for the treatment of people with the disease (Akobeng 2000). The aim of this systematic review is to summarise the current evidence on the use of glutamine for induction of remission in Crohn's disease.

\section{O B J E C T IVES}

1. To evaluate the effectiveness of glutamine supplementation for induction of remission in Crohn's disease.

2. To evaluate adverse events associated with glutamine supplementation in Crohn's disease.

\section{METHODS}

\section{Criteria for considering studies for this review}

\section{Types of studies}

Randomised controlled trials were considered for inclusion.

\section{Types of participants}

Patients of any age with active Crohn's disease were considered for inclusion. Crohn's disease should have been diagnosed by conventional clinical, radiographic, endoscopic and histological criteria. Active disease should have been defined using a recognised Crohn's disease activity index.

\section{Types of interventions}

Randomised controlled trials where glutamine was administered by any route and compared to placebo, an active comparator, or a no intervention control group were considered for inclusion.

\section{Types of outcome measures}

The primary outcome was clinical or endoscopic remission as defined by the primary studies. Secondary outcomes included clinical response as defined by the primary studies, improvement in intestinal permeability, quality of life, growth in children, and adverse events.

\section{Search methods for identification of studies}

\section{Electronic searches}

We searched the following electronic databases from inception to November 15, 2015:

1. MEDLINE;

2. EMBASE;

3. Cochrane Central Register of Controlled Trials; and

4. The Cochrane IBD Group Specialised Register.

There were no language restrictions. The search strategy is reported in Appendix 1.

\section{Searching other resources}

Reference lists from retrieved articles were inspected to identify additional citations that may have been missed by the electronic searches. 


\section{Data collection and analysis}

\section{Selection of studies}

The search results were independently screened by two authors (MG and ME) to identify potentially relevant studies. Two authors (MG and ME), after reading the full texts, independently assessed the eligibility of all trials identified using the pre-specified eligibility criteria stated above. Disagreement among authors was resolved by discussion and agreement was reached by consensus.

\section{Data extraction and management}

A data extraction form was developed and used to extract information on relevant features and results of included studies. The form was based on the Cochrane checklist of items to consider for data extraction (Higgins 2011a). Two authors (ME and MG) independently extracted and recorded data on the predefined checklist. Extracted data included the following items:

A. Methods (methods of randomisation, allocation concealment, blinding, inclusion and exclusion criteria, definition of outcomes); B. Participants (number, age, gender, disease activity, concurrent medication);

C. Interventions (formulation, dose, frequency, duration, method of administration); and

D. Outcomes (clinical remission, intestinal permeability, adverse events) and time of assessment.

\section{Assessment of risk of bias in included studies}

ME and MG independently assessed the methodological quality of each included study using the Cochrane risk of bias tool (Higgins 2011b). The study features assessed included:

a. Random sequence generation;

b. Allocation concealment;

c. Blinding of participants and personnel;

d. Blinding of outcome assessment;

e. Completeness of outcome data;

f. Selective reporting; and

g. Other sources of bias.

We rated each of these factors as 'low risk', 'high risk' or 'unclear risk' of bias.

The overall quality of the evidence supporting the primary outcome was assessed using the GRADE criteria (Guyatt 2008; Schunemann 2011). The GRADE approach appraises the quality of a body of evidence based on the extent to which one can be confident that an estimate of effect reflects the item being assessed. Randomised trials start as high quality evidence, but may be downgraded due to: risk of bias (methodological quality), indirectness of evidence, unexplained heterogeneity, imprecision (sparse data) and publication bias. The overall quality of the evidence for each outcome was determined after considering each of these factors and graded as:
- High: further research is very unlikely to change confidence in the estimate of effect;

- Moderate: further research is likely to have an important impact on confidence in the estimate of effect and may change the estimate;

- Low: further research is very likely to have an important impact on confidence in the estimate of effect and is likely to change the estimate; and

- Very low: any estimate of effect is very uncertain.

\section{Measures of treatment effect}

The Cochrane Collaboration Review Manager (RevMan) software (version 5.3) was used for data analysis. We calculated the risk ratio and corresponding $95 \%$ confidence interval (95\% CI) for dichotomous outcomes using a fixed-effect model. We calculated the mean difference (MD) and corresponding $95 \%$ CI for continuous outcomes measured using the same units. We planned to calculate the standardised mean difference (SMD) and corresponding 95\% CI for continuous outcomes where different scales were used to evaluate the same outcome.

\section{Unit of analysis issues}

If any trial had multiple treatment groups, the 'shared' comparison group was to be divided by the number of treatment groups, and comparisons between each treatment group and the split comparison group were to be treated as independent comparisons.

\section{Dealing with missing data}

Data were analysed according to the intention-to-treat principle. Patients with final missing outcomes were assumed to be treatment failures. A sensitivity analysis was planned to assess the impact on the results of the assumption of treatment failure when data were missing.

\section{Assessment of heterogeneity}

We planned to assess heterogeneity by visually inspecting forest plots and by calculating the $\mathrm{Chi}^{2}$ test of heterogeneity. A P value of $<0.10$ was considered statistically significant. The $\mathrm{I}^{2}$ statistic was to be calculated to quantify the effect of heterogeneity (Higgins 2003).

An $\mathrm{I}^{2}$ value of:

- $<25 \%$ denotes low heterogeneity;

- $\geq 50 \%$ denotes moderate heterogeneity; and

- $\geq 75 \%$ denotes high heterogeneity.

We planed to use a random-effects model in situations of unexplained heterogeneity. When significant heterogeneity was identified, we planned to examine the included studies for sources of both clinical and methodological heterogeneity. We planned to 
explore potential explanations for heterogeneity using sensitivity analysis.

\section{Assessment of reporting biases}

If there was an appropriate number of studies in a pooled analysis (i.e. > 10 studies), we planned to investigate potential publication bias using funnel plots (trial effects versus trial size).

\section{Data synthesis}

Studies were to be pooled for meta-analyses when the interventions, patient groups, outcome measures, and timing of outcome assessment were sufficiently similar (to be determined by consensus).

\section{Subgroup analysis and investigation of heterogeneity}

The following pre-specified subgroup analyses were planned:

a. route of glutamine supplementation;

b. duration of treatment;

c. duration of disease; and

d. disease location (pure colonic disease versus small bowel involvement).

\section{Sensitivity analysis}

Sensitivity analyses were to be conducted based on the following: a. only including patients whose outcome is known (i.e. number of patients who completed the study used as denominator);

b. random-effects versus fixed-effect models; and

c. study quality.

\section{RE S U L T S}

\section{Description of studies}

\section{Results of the search}

A literature search conducted on November 15, 2015 identified 168 records. After duplicates were removed, a total of 143 records remained for review of titles and abstracts. Two authors (AA and MG) independently reviewed the titles and abstracts of these trials and seven records were selected for full text review (see Figure 1). Three articles were excluded (See: Characteristics of excluded studies). Four reports of two trials (total of 42 patients) met the pre-defined inclusion criteria and were included in the review ( Akobeng 2000; Ockenga 2005). 
Figure I. Study flow diagram.

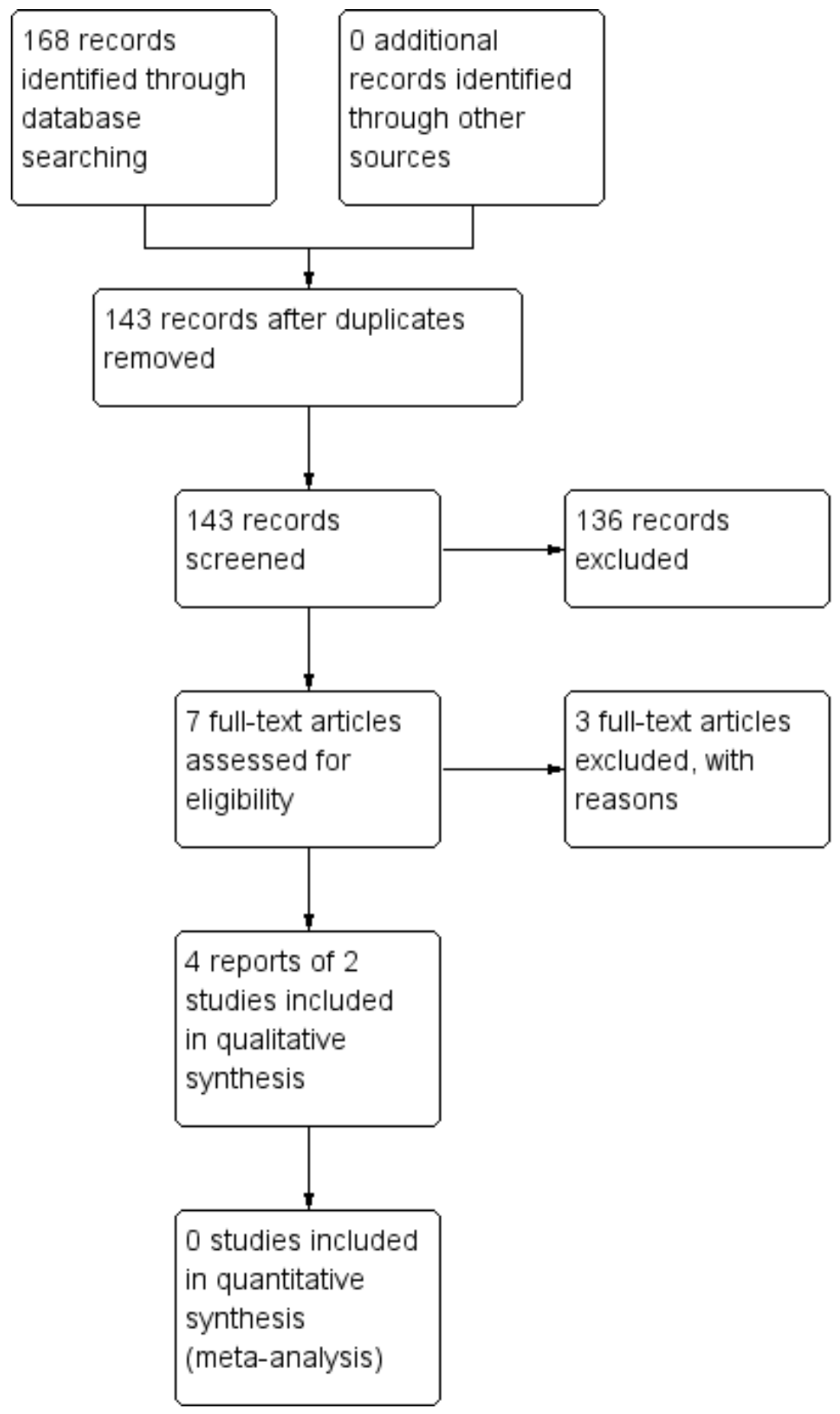




\section{Included studies}

Akobeng 2000 was a double-blind randomised controlled trial conducted at a single centre in the UK. This study randomised 18 patients ( $<16$ years old) with active Crohn's disease, defined by a Paediatric Crohn's Disease Activity Index (PCDAI) of $>12$. Participants received either a standard polymeric diet with a low glutamine content ( $4 \%$ of amino acid composition) or a glutamineenriched polymeric diet ( $42 \%$ of amino acid composition) for four weeks as primary therapy for active Crohn's disease. The two diets were isocaloric and isonitrogenous with an identical essential amino acid profile. Patients were encouraged to consume the diet orally. If this was not possible the diet was administered via a finebore nasogastric tube. The primary study outcome was clinical remission at four weeks, defined as a PCDAI $<10$. Secondary outcomes included changes in clinical and laboratory parameters of disease activity after four weeks. Exclusion criteria included treatment at entry with prednisolone at doses higher than $5 \mathrm{mg} /$ day, and treatment with immunosuppressive agents. The use of concurrent medications was not reported. Two patients, both from the glutamine-enriched diet group, were withdrawn from the trial because of non-tolerance of the diet. Analysis of remission rates was performed on an intention-to-treat basis. Data from the same trial on intestinal permeability and serum antioxidant concentrations were published separately (Akobeng 2000a; Akobeng 2007). Ockenga 2005 was a randomised controlled trial conducted at a single centre in Germany. The study randomised 24 adults (> 18 years of age) with acute exacerbation of inflammatory bowel disease (19 Crohn's disease, 5 ulcerative colitis) who were being considered for total parenteral nutrition (TPN). Patients in the glutamine group received $0.3 \mathrm{~g} / \mathrm{kg} / \mathrm{day}$ alanyl-glutamine (resulting in $0.2 \mathrm{~g} / \mathrm{kg} /$ day glutamine) which was added to $1.2 \mathrm{~g} / \mathrm{kg} /$ day of standard amino-acid solution. Patients in the control group received $1.5 \mathrm{~g} / \mathrm{kg} /$ day amino acids in a standard solution which did not contain glutamine. The study investigators, patients, nurses, and primary physicians were unaware of treatment assignment. Exclusion criteria included non consent, receipt of TPN within two weeks of entry, pregnancy, and renal failure. All patients were treated with mesalazine (dosage not specified). Ten patients in the glutamine group received prednisolone (mean dose $0.85 \mathrm{mg}$ / $\mathrm{kg} /$ day \pm 0.66$)$, whilst 12 patients in the control group received prednisolone (mean dose $0.73 \mathrm{mg} / \mathrm{kg} / \mathrm{day} \pm 0.20$ ). One patient in the glutamine group was treated with azathioprine compared to three patients in the control group. TPN was administered for at least one week. The primary study outcomes were glutamine plasma concentrations and intestinal permeability after one week. Secondary outcomes included protein catabolism, disease activity measured by the Crohn's Disease Activity Index (CDAI), infectious complications, and duration of TPN.

See the Characteristics of included studies table for further information on the included studies.

\section{Risk of bias in included studies}

Both included studies used computer-generated randomisation codes and sealed opaque envelopes for allocation concealment and were rated as low risk of bias for these items. The Akobeng 2000 study was rated as low risk of bias for participants and personnel and for outcome assessors. The study double-blind and the two diets were not distinguishable in appearance, smell, or taste and the randomisation code was not broken until the study was completed. There were no drop-outs in Akobeng 2000 and the study was rated as low risk of bias for incomplete outcome data. Akobeng 2000 reported on all pre-specified outcomes and was rated as low risk of bias for selective outcome reporting. There did not appear to be any other apparent sources of bias and Akobeng 2000 was rated as low risk of other sources of bias. The Ockenga 2005 study did not describe methods for blinding of participants and personnel, and for blinding of outcome assessment and was rated as unclear risk of bias for these items. Intestinal permeability data were available for 14 of 19 patients with Crohn's disease in the Ockenga 2005 study. Incomplete outcomes data was judged to be at low risk of bias. Ockenga 2005 reported on all pre-specified outcomes and was rated as low risk of bias for selective outcome reporting. There did not appear to be any other apparent sources of bias and Ockenga 2005 was rated as low risk of bias for other sources of bias. The risk of bias assessment is summarised in Figure 2. 
Figure 2. Risk of bias summary: review authors' judgements about each risk of bias item for each included study.

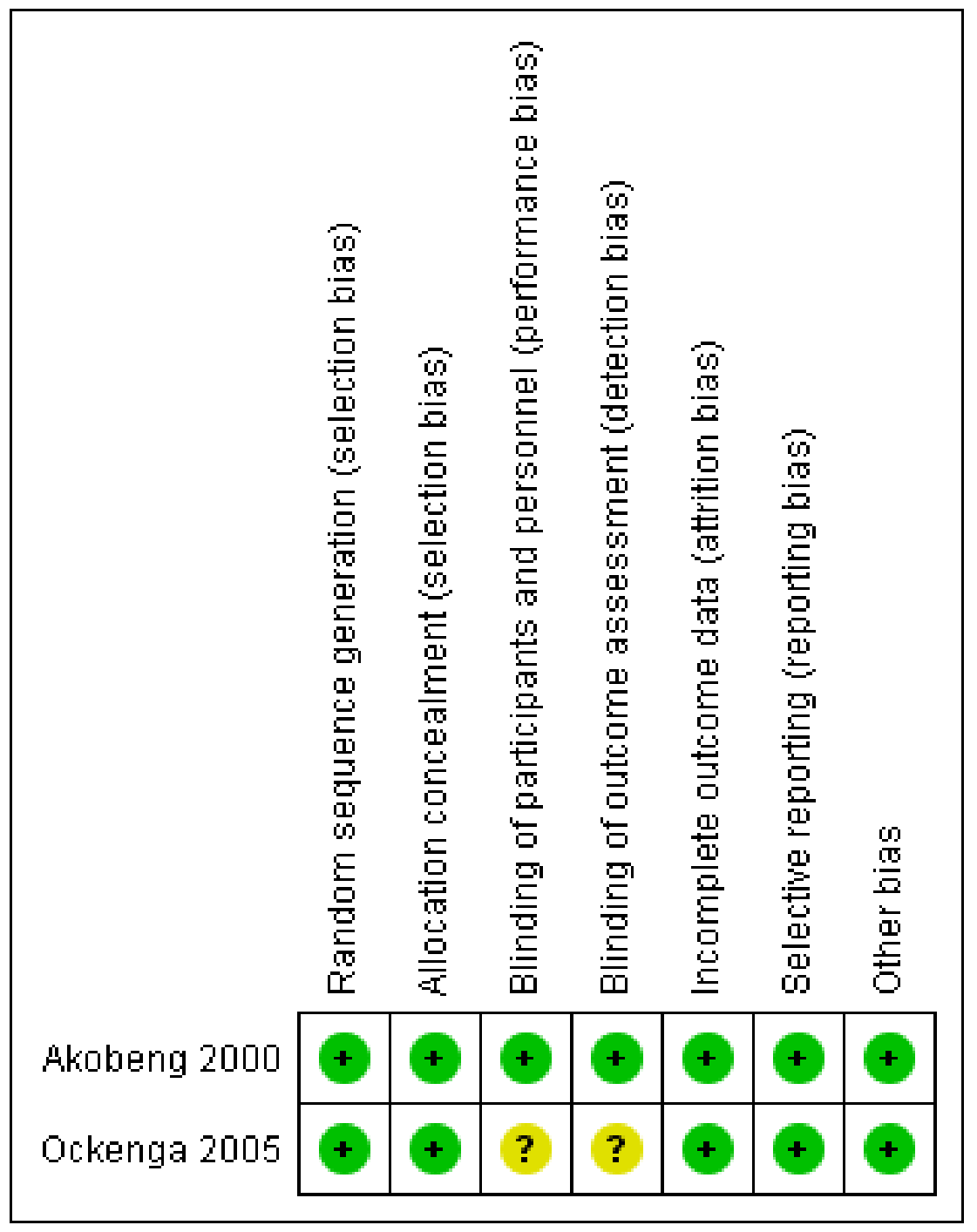




\section{Effects of interventions}

See: Summary of findings for the main comparison

See Summary of findings for the main comparison

Clinical remission: One study investigated this outcome ( Akobeng 2000). There was no statistically significant difference in remission rates between patients who received the glutamineenriched diet compared to those who received a standard low glutamine diet. Forty-four per cent (4/9) of patients who received the glutamine-enriched diet achieved clinical remission (PCDAI <10) after 4 weeks compared to $56 \%(5 / 9)$ of those who received the standard low glutamine diet (RR 0.80, 95\% CI 0.31 to 2.04; See Figure 3). A GRADE analysis indicated that the overall quality of evidence for this outcome was low due to serious imprecision (9 events, see Summary of findings for the main comparison).

Figure 3. Forest plot of comparison: I Glutamine-enriched diet versus standard diet, outcome: I.I Clinical remission.

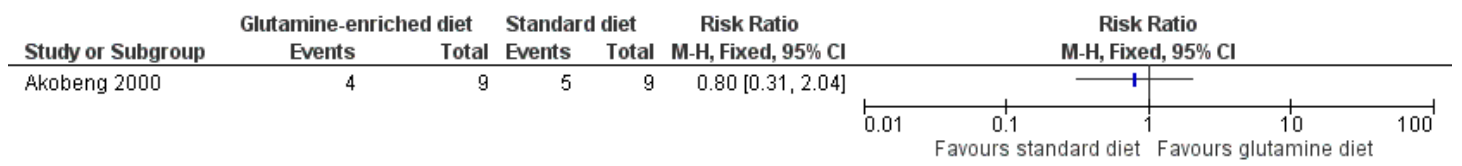

Endoscopic remission: None of the included studies reported on this outcome.

Clinical response: None of the included studies reported on this outcome.

Intestinal permeability: Both trials investigated this outcome. In Akobeng 2000 the mean lactulose/mannitol permeability ratio decreased from 0.103 to 0.037 in the standard diet group ( $\mathrm{P}$ $=0.012$ ) after 4 weeks, and reduced from 0.068 to 0.043 in the glutamine-supplemented group $(\mathrm{P}=0.058)$. There was no statis- tically significant difference between the two groups with regard to changes in lactulose/mannitol permeability ratios $(\mathrm{P}=0.239)$. In Ockenga 2005, the mean lactulose/xylose ratio at baseline was $0.042 \pm 0.03$ with no difference between patients with Crohn's disease or ulcerative colitis $(0.043 \pm 0.038$ versus $0.040 \pm 0.027, \mathrm{P}$ $>0.05$ ). After one week, changes in lactulose/xylose permeability ratio were not significantly different in patients who received glutamine compared to those who did not receive glutamine (MD 0.01, 95\% CI -0.04 to 0.02; See Figure 4).

Figure 4. Forest plot of comparison: I Glutamine-enriched diet versus standard diet, outcome: I.2 Intestinal permeability.

\begin{tabular}{|c|c|c|c|c|c|c|c|c|c|c|c|}
\hline Study or Subgroup & \multicolumn{3}{|c|}{ Glutamine-enriched TPN } & \multicolumn{3}{|c|}{ Standard TPN } & $\begin{array}{l}\text { Mean Difference } \\
\text { IV, Fixed, } 95 \% \mathrm{CI}\end{array}$ & \multicolumn{4}{|c|}{$\begin{array}{l}\text { Mean Difference } \\
\text { IV, Fixed, } 95 \% \mathrm{Cl}\end{array}$} \\
\hline & & & & & & & & -0.2 & -0.1 & 0.1 & 0.2 \\
\hline
\end{tabular}

Quality of life: None of the included studies reported on this outcome.

Growth in children: None of the included studies reported on this outcome.
Adverse events: The stated purpose of Akobeng 2000 was to compare the efficacy of the glutamine-enriched diet with a standard low-glutamine diet for the treatment of active Crohn's disease. 
No specific adverse event outcomes were reported but the authors have confirmed that no serious adverse events were noted in either group (Akobeng, personal communication). In Ockenga 2005, three central catheter infections with positive blood cultures were diagnosed in the glutamine group compared to none in the control group (RR 7.00, 95\% CI 0.04 to 124.44; See Figure 5).

Figure 5. Forest plot of comparison: I Glutamine-enriched diet versus standard diet, outcome: I.3 Central catheter infections.

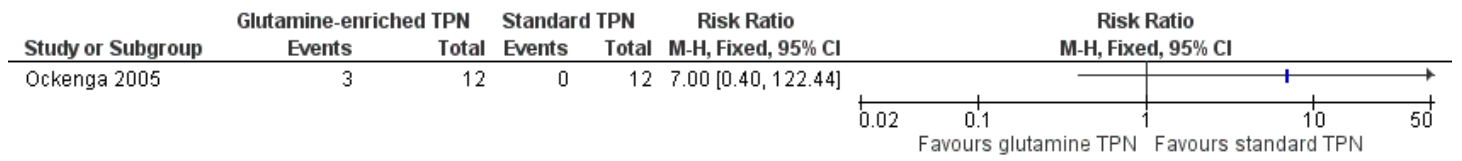

Other outcomes: Both studies evaluated changes in measures of disease activity or symptoms. In Akobeng 2000, reduction in mean PCDAI was significantly higher in the control group compared to the glutamine-enriched group after four weeks but there were no statistically significant differences in changes in platelet count, orosomucoid, or weight. In Ockenga 2005, glutamine supplementation was not associated with any statistically significant changes in CDAI, white cell count, frequency of diarrhoea, pain, or extraintestinal symptoms. Ockenga 2005 also reported that the length of hospital stay did not differ significantly between patients who received glutamine and those who did not. Akobeng 2000 investigated changes in plasma antioxidant concentration. After 4 weeks, there were no statistically significant differences between patients who received the glutamine-enriched diet compared to those who received a standard diet with regard to changes in plasma concentrations of selenium $(P=0.076)$, urate $(P=0.053)$, glutathione $(\mathrm{P}=0.815)$, vitamin $\mathrm{E}(\mathrm{P}=0.245)$, vitamin $\mathrm{C}(\mathrm{P}=0.639)$, and malondialdehyde $(\mathrm{P}=0.190)$. There was however a statistically significant increase in the mean vitamin A level in the standard diet group compared to the glutamine-enriched diet group $(\mathrm{P}=$ 0.018). In Ockenga 2005, plasma concentrations of glutamine did not change significantly in either group throughout the study.

\section{DISCUSSION}

\section{Summary of main results}

Glutamine, the principal respiratory substrate for enterocytes is known to be important for maintenance of intestinal metabolism, structure and function. It has therefore been suggested that it may facilitate the induction of remission in people with Crohn's disease. We have found no evidence in this review to suggest that glutamine supplemention provides any benefit in the treatment of active Crohn's disease.

Two trials were included in the review (Akobeng 2000; Ockenga 2005). The study populations, nature of interventions, and the way outcomes were assessed differed between the two studies and it was not possible to pool data for meta-analysis. Akobeng 2000 found no statistically significant difference in clinical remission rates between patients who were supplemented with glutamine and those who were not. Neither study demonstrated any significant changes in intestinal permeability between patients supplemented with glutamine and those who were not. In Akobeng 2000, the reduction in mean PCDAI was significantly higher in patients who received a standard low glutamine diet compared to those who received the glutamine-enriched diet. In Ockenga 2005, glutamine supplementation was not associated with any statistically significant differences in CDAI, white cell count, frequency of diarrhoea, pain, extraintestinal symptoms or length of hospital stay. Neither study reported data on endoscopic remission, clinical response, or quality of life.

Adverse event data were not well documented in the included studies. Akobeng 2000 did not report on any specific adverse event outcomes. However, the authors have confirmed that no serious adverse events were noted in either group. Ockenga 2005 reported that three catheter infections with positive blood cultures were diagnosed in the glutamine group compared to none in the control group. Ockenga 2005 did not report on any other adverse events.

\section{Overall completeness and applicability of evidence}

The results of this systematic review, which are applicable to patients with active Crohn's disease, should be interpreted with caution. Although the results of the included studies did not support 
the hypothesis that glutamine supplementation may be useful in active Crohn's disease, both studies were limited by small sample sizes and serious imprecision. For the primary outcome, induction of clinical remission, the point estimate of the risk ratio $(0.80)$ suggests that patients who received the glutamine-enriched polymeric diet were $20 \%$ less likely to enter remission compared to patients who received the standard low-glutamine diet. However, the $95 \%$ confidence interval includes both a reduction in likelihood of remission of about $70 \%$, and a two fold increase in the likelihood of remission ( $95 \%$ CI 0.31 to 2.04). Larger trials are required to determine if glutamine provides any benefit for induction of remission in Crohn's disease.

\section{Quality of the evidence}

The Akobeng 2000 study was judged to be at low risk of bias. Ockenga 2005 id not describe the methods used for blinding of participants and personnel, or for blinding of outcome assessment and was rated as unclear risk of bias for these domains. Ockenga 2005 was rated as low risk of bias for the other items. The GRADE rating for the evidence supporting the primary outcome (clinical remission) was low because the small sample size and low event rates resulted in serious imprecision.

\section{Potential biases in the review process}

A comprehensive literature search was performed to reduce potential bias and identify all eligible studies. Two review authors independently assessed studies for inclusion, extracted data and rated study quality. There are limitations to this review. The two included studies were small and it was not possible to pool data for meta-analysis because of significant differences in the study populations, nature of interventions, and the way outcomes were assessed.

\section{Agreements and disagreements with other studies or reviews}

To our knowledge, there are no other published systematic reviews that assess the efficacy and safety of glutamine in active Crohn's disease.

\section{A U THORS'CONCLUSIONS}

\section{Implications for practice}

Currently there is insufficient evidence to allow firm conclusions regarding the efficacy and safety of glutamine for induction of remission in Crohn's disease. Data from two small studies suggest that glutamine supplementation may not be beneficial in active Crohn's disease but these results need to be interpreted with caution as they are based on small numbers of patients.

\section{Implications for research}

This review highlights the need for high quality, adequately powered randomised controlled trials to investigate the efficacy and safety of glutamine for induction of remission in Crohn's disease.

\section{ACKNOWLEDGEMENTS}

Funding for the IBD/FBD Review Group (September 1, 2010 - August 31, 2015) was provided by the Canadian Institutes of Health Research (CIHR) Knowledge Translation Branch (CON - 105529) and the CIHR Institutes of Nutrition, Metabolism and Diabetes (INMD); and Infection and Immunity (III) and the Ontario Ministry of Health and Long Term Care (HLTC3968FL2010-2235).

\section{R E F E R E N E S}

\section{References to studies included in this review}

Akobeng 2000 \{published data only\}

* Akobeng AK, Miller V, Stanton J, Elbadri AM, Thomas

AG. Double-blind randomized controlled trial of glutamineenriched polymeric diet in the treatment of active Crohn's disease. Journal of Pediatric Gastroenterology and Nutrition 2000;30(1):78-84.

Akobeng AK, Richmond K, Miller V, Thomas AG. Effect of exclusive enteral nutritional treatment on plasma antioxidant concentrations in childhood Crohn's disease. Clinical Nutrition 2007;26:51-6.

Akobeng AK, Thomas AG, Richmond K. Glutamine supplementation and intestinal permeability in Crohn's disease.. Journal of Parenteral and Enteral Nutrition 2000; 24:196.

Ockenga 2005 \{published data only\}

Ockenga J, Borchert K, Stuber E, Lochs H, Manns MP, Bischoff SC. Glutamine-enriched total parenteral nutrition in patients with inflammatory bowel disease. European Journal of Clinical Nutrition 2005;59(11):1302-9.

\section{References to studies excluded from this review}

Benjamin 2011 \{published data only\} Benjamin J, Makharia G, Ahuja V, Rajan KDA, Kalaivani M, Gupta SD, Joshi YK. Glutamine and whey protein improve intestinal permeability and morphology in patients 
with Crohn's disease: a randomized controlled trial.

Digestive Diseases and Sciences 2011;57:1000-12.

\section{Coeffier 2010 \{published data only\}}

Coeffier M, Marion-Letellier R, Dechelotte P. Potential for amino acid supplementation during inflammatory bowel diseases. Inflammatory Bowel Diseases 2010;16:518-24.

\section{Hond 1999 \{published data only\}}

Hond ED, Hiele M, Peeters M, Ghoos Y, Rutgeerts M. Effect of long-term oral glutamine supplements on small intestinal permeability in patients with Crohn's disease. Journal of Parenteral and Enteral Nutrition 1999;23:7-11.

\section{Additional references}

\section{Akobeng 2000a}

Akobeng AK, Thomas AG, Richmond K. Glutamine supplementation and intestinal permeability in Crohn's disease. Journal of Parenteral and Enteral Nutrition 2000;24: 196.

Akobeng 2007

Akobeng AK, Richmond K, Miller V, Thomas AG. Effect of exclusive enteral nutritional treatment on plasma antioxidant concentrations in childhood Crohn's disease. Clinical Nutrition 2007;26:51-6.

Coeffier 2003

Coeffier M, Marion R, Ducrotte P, Dechelotte P. Modulating effect of glutamine in IL-1beta-induced cytokine production by human gut. Clinical Nutrition 2003;22(4):407-13.

Fox 1988

Fox AD, Kripke SA, De Paula J, Berman JM, Settle RG, Rombeau JL. Effect of a glutamine-supplemented enteral diet on methotrexate-induced enterocolitis. Journal of Parenteral and Enteral Nutrition 1988;12(4):325-31.

\section{Fujita 2005}

Fujita T, Sakurai K. Efficacy of glutamine-enriched enteral nutrition in an experimental model of mucosal ulcerative colitis. British Journal of Surgery 2005;82(6):749-51.

\section{Guyatt 2008}

Guyatt GH, Oxman AD, Vist GE, Kunz R, Falck-Ytter Y, Alonso-Coello P, et al. GRADE: an emerging consensus on rating quality of evidence and strength of recommendations. BMJ 2008;336:924-6.

Hall 1996

Hall JC, Heel K, McCauley R. Glutamine. British Journal of Surgery 1996;83(3):305-12.

Higgins 2003

Higgins JPT, Thompson SG, Deeks JJ, Altman DG. Measuring inconsistency in meta-analyses. BMJ 2003;327 (7414):557-60.

Higgins 2011a

Higgins JPT, Deeks JJ (editors). Chapter 7: Selecting studies and collecting data. In: Higgins JPT, Green S editor(s). Cochrane Handbook for Systematic Reviews of Interventions Version 5.1.0 (updated March 2011).
The Cochrane Collaboration, 2011. Available from www.cochrane-handbook.org.

\section{Higgins 2011b}

Higgins JPT, Altman DG, Sterne JAC (editors). Chapter 8: Assessing risk of bias in included studies. In: Higgins JPT, Green S editor(s). Cochrane Handbook for Systematic Reviews of Interventions Version 5.1.0 (updated March 2011). The Cochrane Collaboration, 2011. Available from www.cochrane-handbook.org.

\section{Kangas 1986}

Kangas E, Matikainen M, Auvinen O, Harju E, Inkovaara J, Mäki M. Clinical features of Crohn's disease: a clinical study of one hundred patients found in an unselected population. International Surgery 1986;71(4):256-9.

\section{Katz 1989}

Katz KD, Hollander D, Vadheim CM, McElree C, Delahunty T, Dadufalza VD, et al. Intestinal permeability in patients with Crohn's disease and their healthy relatives. Gastroenterology 1989;97(4):927-31.

\section{Lacey 1990}

Lacey JM, Wilmore DW. Is glutamine a conditionally essential amino acid?. Nutrition Reviews 1990;48(8): 297-309.

\section{Marion 2004}

Marion R, Coëffier MM, Gargala G, Ducrotté P, Déchelotte PP. Glutamine and CXC chemokines IL-8, Mig, IP-10 and I-TAC in human intestinal epithelial cells. Clinical Nutrition 2004;23(4):579-85.

\section{Schunemann 2011}

Schünemann HJ, Oxman AD, Vist GE, Higgins JPT, Deeks JJ, Glasziou P, Guyatt GH. Chapter 12: Interpreting results and drawing conclusions. In: Higgins JPT, Green S editor(s). Cochrane Handbook for Systematic Reviews of Interventions Version 5.1.0 (updated March 2011). The Cochrane Collaboration, 2011. Available from www.cochrane-handbook.org.

Sido 2006

Sido B, Seel C, Hochlehnert A, Breitkreutz R, Dröge W. Low intestinal glutamine level and low glutaminase activity in Crohn's disease: a rational for glutamine supplementation?. Digestive Diseases and Sciences 2006;51 (12):2170-9.

\section{Stehle 1989}

Stehle P, Zander J, Mertes N, Albers S, Puchstein C, Lawin $\mathrm{P}$, et al. Effects of parenteral glutamine peptide supplements on muscle glutamine loss and nitrogen balance after major surgery. Lancet 1989;1(8632):231-3.

\section{Thomas 1991}

Thomas AG. Nutritional disturbances in childhood Crohn's disease. MD Thesis, University of Manchester 1991.

\section{Thomas 1992}

Thomas AG, Miller V, Taylor F, Maycock P, Scrimgeour $\mathrm{CM}$, Rennie MJ. Whole body protein turnover in childhood Crohn's disease. Gut 1992;33(5):675-7. 
Van der Hurst 1993

Van der Hulst RR, Van Kreel BK, Von Meyenfeldt MF,

Brummer RJ, Arends JW, Deutz NE, et al. Glutamine and the preservation of gut integrity. Lancet 1993;341(8857): 1363-5.

\section{Windmueller 1978}

Windmueller HG, Spaeth AE. Identification of ketone bodies and glutamine as the major respiratory fuels in vivo for postabsorptive rat small intestine. Journal of Biological Chemistry 1978;253(1):69-76.

* Indicates the major publication for the study 


\section{CHARACTERISTICS OF STUDIES}

\section{Characteristics of included studies [ordered by study ID]}

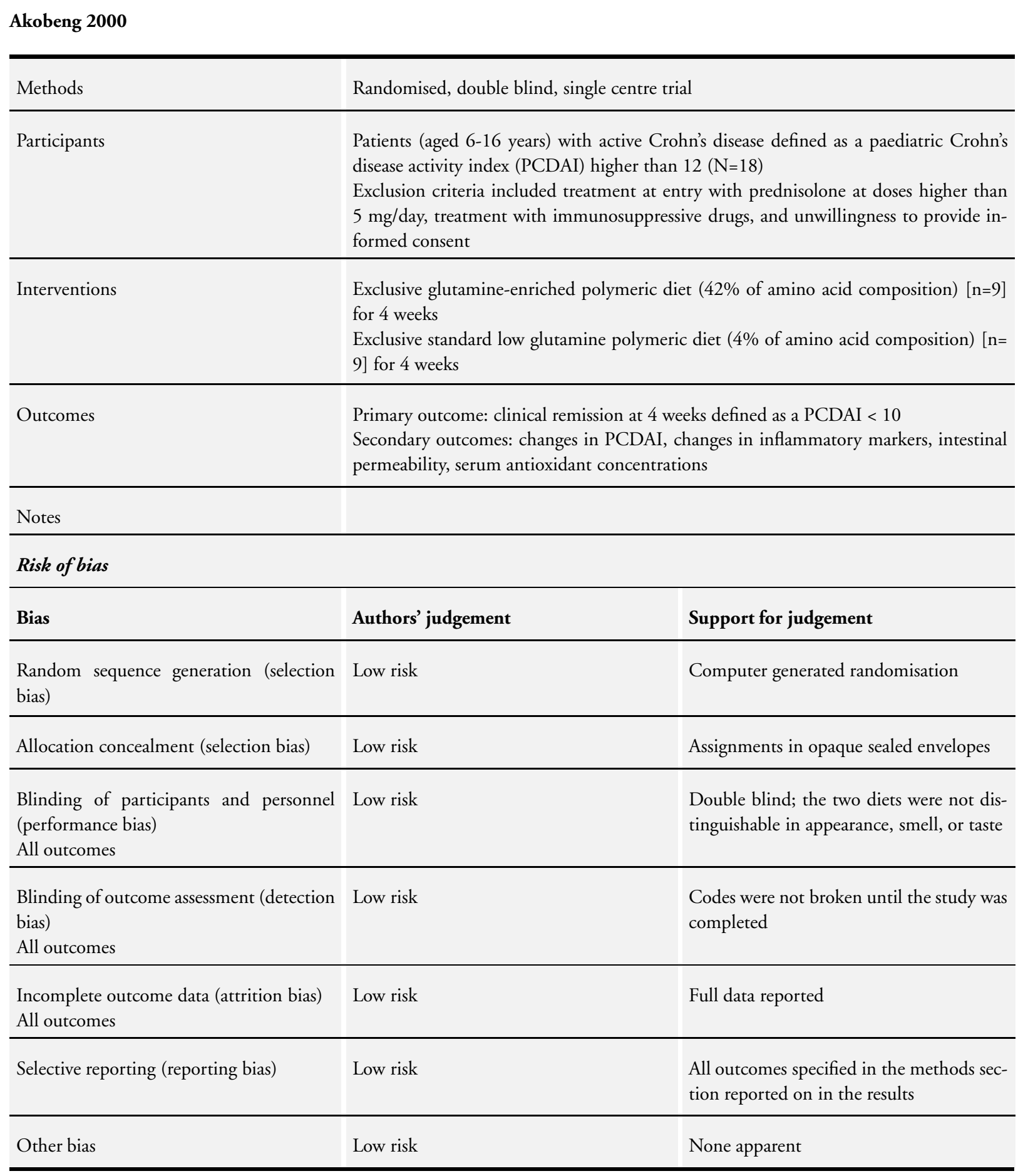


Ockenga 2005

\begin{tabular}{|c|c|c|}
\hline Methods & \multicolumn{2}{|c|}{ Randomised, blinded, single centre } \\
\hline Participants & \multicolumn{2}{|c|}{$\begin{array}{l}\text { Adults with acute exacerbation of inflammatory bowel disease (19 Crohn's disease, } 5 \\
\text { ulcerative colitis) who were being considered for TPN ( } N=24) \\
\text { Exclusion criteria included: not consenting to the study, on TPN within } 2 \text { weeks before } \\
\text { study, being pregnant, having renal failure }\end{array}$} \\
\hline Interventions & \multicolumn{2}{|c|}{$\begin{array}{l}\text { TPN with } 1.5 \mathrm{~g} / \mathrm{kg} \text { body weight of a standard amino acid [ } \mathrm{n}=12 \text { ] for at least } 1 \text { week } \\
\text { TPN with } 1.2 \mathrm{~g} / \mathrm{kg} \text { body weight of a standard amino acid and } 0.3 \mathrm{~g} / \mathrm{kg} \text { L-alanine-L- } \\
\text { glutamine [ } \mathrm{n}=12 \text { ] for at least one week }\end{array}$} \\
\hline Outcomes & \multicolumn{2}{|c|}{$\begin{array}{l}\text { Primary outcomes: Glutamine plasma concentrations, intestinal permeability } \\
\text { Secondary outcomes: disease activity, infectious complications, duration of TPN }\end{array}$} \\
\hline \multicolumn{3}{|l|}{ Notes } \\
\hline \multicolumn{3}{|l|}{ Risk of bias } \\
\hline Bias & Authors' judgement & Support for judgement \\
\hline $\begin{array}{l}\text { Random sequence generation (selection } \\
\text { bias) }\end{array}$ & Low risk & $\begin{array}{l}\text { Treatment groups generated by random order se- } \\
\text { quence }\end{array}$ \\
\hline Allocation concealment (selection bias) & Low risk & Assignments in sealed opaque envelopes \\
\hline $\begin{array}{l}\text { Blinding of participants and personnel } \\
\text { (performance bias) } \\
\text { All outcomes }\end{array}$ & Unclear risk & $\begin{array}{l}\text { Authors say it was blinded but unclear how this } \\
\text { was achieved }\end{array}$ \\
\hline $\begin{array}{l}\text { Blinding of outcome assessment (detection } \\
\text { bias) } \\
\text { All outcomes }\end{array}$ & Unclear risk & Not described \\
\hline $\begin{array}{l}\text { Incomplete outcome data (attrition bias) } \\
\text { All outcomes }\end{array}$ & Low risk & $\begin{array}{l}\text { Intestinal permeability data were available for } 14 \\
\text { of } 19 \text { patients with Crohn's disease }\end{array}$ \\
\hline Selective reporting (reporting bias) & Low risk & $\begin{array}{l}\text { All outcomes specified in the methods section re- } \\
\text { ported on in the results }\end{array}$ \\
\hline Other bias & Low risk & None apparent \\
\hline
\end{tabular}

TPN: total parenteral nutrition. 
Characteristics of excluded studies [ordered by study ID]

\begin{tabular}{ll}
\hline Study & Reason for exclusion \\
\hline Benjamin 2011 & Participants did not have active disease \\
\hline Coeffier 2010 & Review article \\
\hline Hond 1999 & Participants did not have active disease \\
\hline
\end{tabular}


DATA ANDANALYSES

Comparison 1. Glutamine-enriched diet versus standard diet

\begin{tabular}{lcll} 
Outcome or subgroup title & $\begin{array}{c}\text { No. of } \\
\text { studies }\end{array}$ & $\begin{array}{c}\text { No. of } \\
\text { participants }\end{array}$ & \multicolumn{1}{c}{ Statistical method } \\
\hline 1 Clinical remission & 1 & Risk Ratio (M-H, Fixed, 95\% CI) & Totals not selected \\
2 Intestinal permeability & 1 & Mean Difference (IV, Fixed, 95\% CI) & Totals not selected \\
3 Central catheter infections & 1 & Risk Ratio (M-H, Fixed, 95\% CI) & Totals not selected \\
\hline
\end{tabular}

Analysis I.I. Comparison I Glutamine-enriched diet versus standard diet, Outcome I Clinical remission.

Review: Glutamine for induction of remission in Crohn's disease

Comparison: I Glutamine-enriched diet versus standard diet

Outcome: I Clinical remission

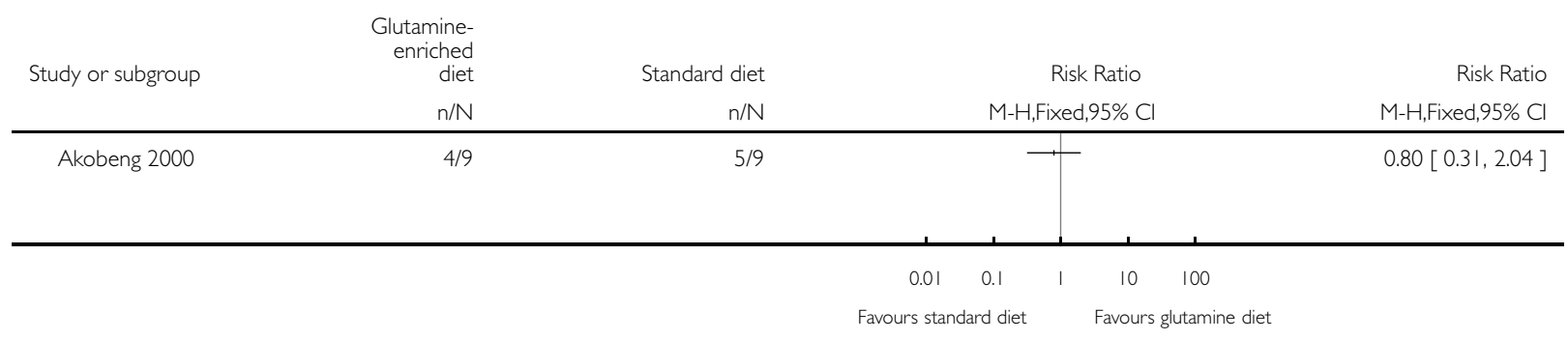


Analysis I.2. Comparison I Glutamine-enriched diet versus standard diet, Outcome 2 Intestinal permeability.

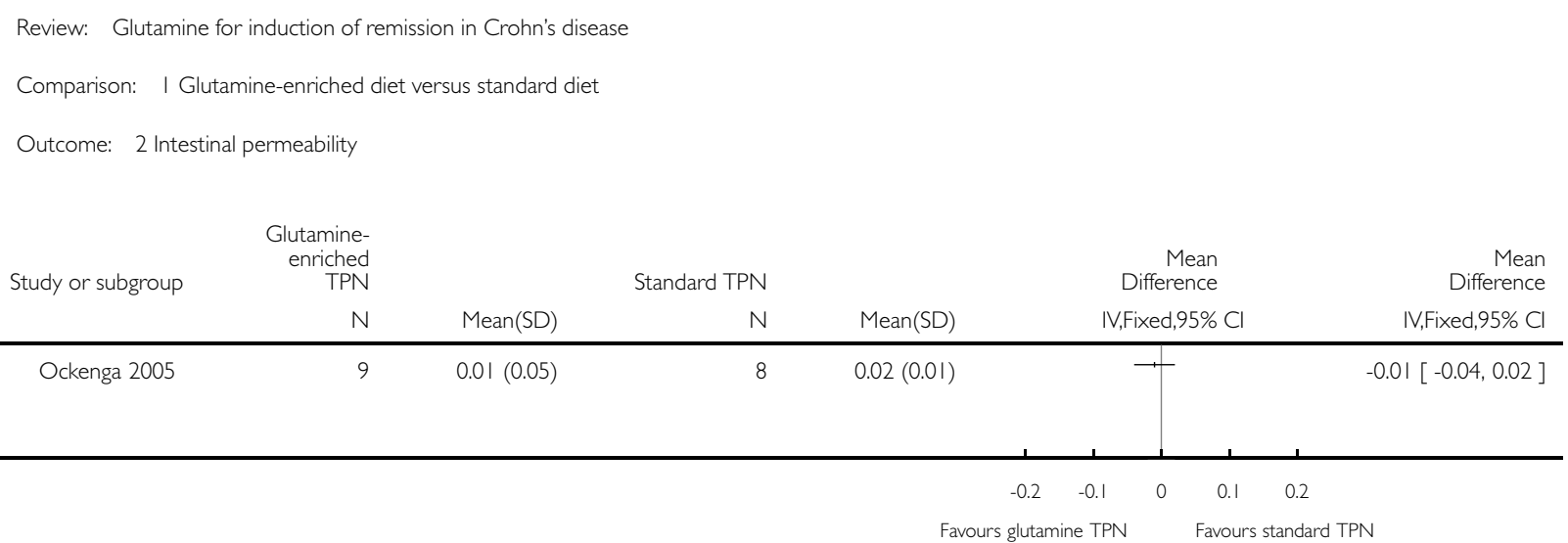

Analysis I.3. Comparison I Glutamine-enriched diet versus standard diet, Outcome 3 Central catheter infections.

Review: Glutamine for induction of remission in Crohn's disease

Comparison: I Glutamine-enriched diet versus standard diet

Outcome: 3 Central catheter infections

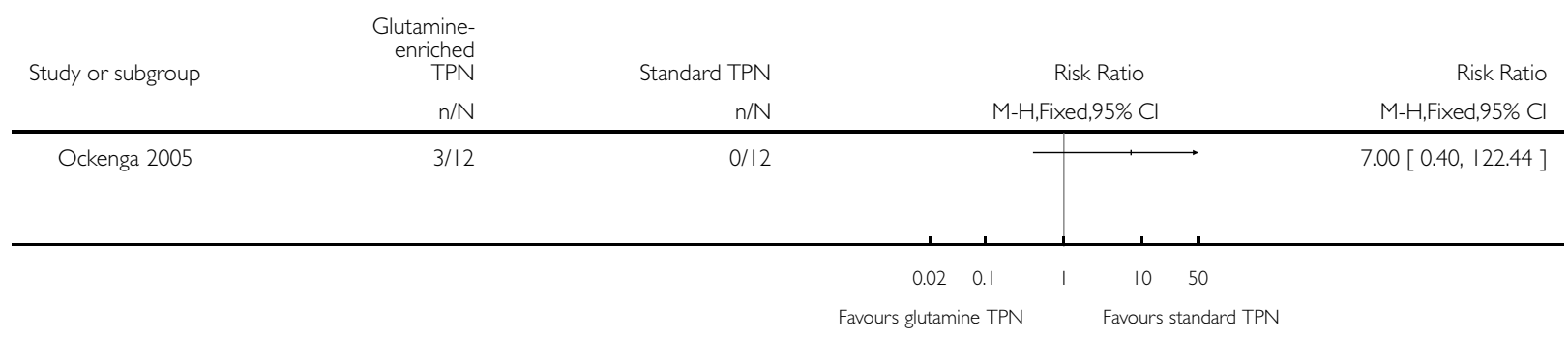




\section{A P P E N D I C ES}

\section{Appendix I. Search strategy}

\section{PubMed}

1. Crohn* disease

2. Crohn disease $(\mathrm{MeSH})$

3. Regional enteritis

4. Ileitis

5. Ileitis (MeSH)

6. Inflammatory bowel disease

7. Inflammatory bowel diseases (MeSH)

8. 1 OR 2 OR 3 OR 4 OR 5 OR 6 OR 7

9. Glutamine

10. 8 AND 9

EMBASE

1. crohn disease.mp. or crohn disease/

2. crohn's disease.mp. or crohn's disease

3. ileitis.mp. or ileitis/

4. inflammatory bowel disease.mp. or enteritis/ or inflammatory bowel disease

5. 1 or 2 or 3 or 4

6. Glutamine/ or glutamine.mp.

7.5 and 6

Cochrane Central Register of Controlled Trials

1. Crohn's disease

2. Crohn disease

3. inflammatory bowel disease

4. 1 or 2 or 3

5. glutamine

6. 4 and 5

\section{CONTRIBUTIONSOFAUTHORS}

- AA conceived and coordinated the review, helped develop the protocol, searched for and screened studies, performed data entry and data analysis, and helped write the review text.

- ME searched for and screened studies, performed data extraction, assessed study quality, checked data and helped write the review text.

- MG searched for and screened studies, performed data extraction, assessed study quality, checked data and helped write the review text.

\section{DECLARATIONSOF INTEREST}

Dr. AK Akobeng was one of the lead investigators for a randomised controlled trial that investigated the role of enteral glutamine in childhood Crohn's disease. Dr Akobeng has no known financial activities to declare.

Mamoun Elawad: None known.

Morris Gordon has received a travel grants from Vifor / Warner Chilcott (DDW 2013), Ferring / Danone (Advances in IBD 2014), Tillotts (Advances in IBD 2015) to attend gastroenterology conferences and travel grants from Abbot Nutrition, Clinova, Biogai, and Danone for attending meetings to present research. All of these activities are outside the submitted work. 


\section{DIFFERENCES BETWEEN PROTOCOLANDREVIEW}

In the protocol we planned to contact leaders in the field to identify applicable studies. This was not undertaken. In line with current Cochrane Collaboration recommendations, we assessed the methodological quality of each included study using the risk of bias tool (Higgins 2011b) instead of the Jadad scale mentioned in the original protocol. We also assessed the quality of the overall evidence supporting the primary outcome using the GRADE approach (Guyatt 2008; Schunemann 2011). In addition to the outcomes prespecified in the protocol, we also reported on other outcomes mentioned in the included primary studies. 